\title{
Synthesis, Crystal Structure, Hirshfeld Surface, Energy Framework and Molecular Docking of 2-(((6-Methoxy Pyridin-3-Yl) Imino) Methyl)Phenol
}

By M. Singh, S. Anthal, P. Akhileshwari, M. A. Sridhar, H. M. Vinusha, S. Bindya, M. Begum, R. K. Chandrasekaran, M. Saminathan \& R. Kant

Abstract- The structure of 2-(((6-methoxypyridin-3-yl)imino)methyl)phenol (MPIMP) $\left(\mathrm{C}_{13} \mathrm{H}_{12} \mathrm{~N}_{2} \mathrm{O}_{2}\right)$ has been determined by X-ray diffraction methods. It crystallizes in the tetragonal crystal system with space group $\mathrm{P} 44_{2} / \mathrm{n}$ and unit cell dimensions $\mathrm{a}=14.2958(3) \AA, b=14.2958(3) \AA, c=11.0179(3) \AA, V=2251.73(12)$ $\AA^{3}, Z=8$. The structure has been refined by full-matrix least square procedure to a final R-value of $0.0518\left(w_{2}=0.1312\right)$ for 1709 observed reflections. The molecules linked via two intermolecular $(\mathrm{C}-\mathrm{H}$...N and $\mathrm{C}-\mathrm{H} . . \mathrm{O}$ ) hydrogen bonds. The crystal structure was further stabilized by a strong intramolecular $\mathrm{N}$ $\mathrm{H}$...O hydrogen bond. The Hirshfeld surface analysis reveals the interaction contacts of the molecule and the strength of molecular packing in the crystal. The energy framework has been performed through different intermolecular interaction energies for structural stability. The molecular docking of MPIMP was performed against tuberculosis enzyme Decaprenyl-phosphoryl-b-Dribose 20-epimerase (DprE1, PDB code: $4 \mathrm{KW} 5$ ) to reconnoiter the binding interactions at the active sites.

Keywords: crystal structure, x-ray diffraction, direct methods, intermolecular interactions, and molecular docking.

GJSFR-B Classification: FOR Code: 260101

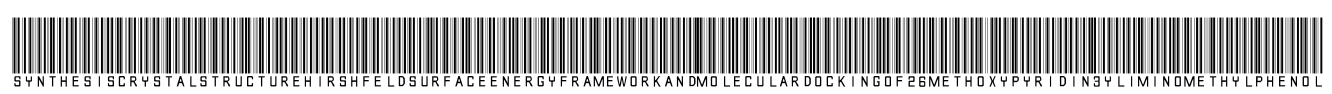

Strictly as per the compliance and regulations of:

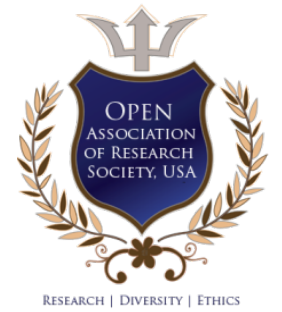

(C) 2021. M. Singh, S. Anthal, P. Akhileshwari, M. A. Sridhar, H. M. Vinusha, S. Bindya, M. Begum, R. K. Chandrasekaran, M. Saminathan \& R. Kant. This research/review article is distributed under the terms of the Attribution-NonCommercialNoDerivatives 4.0 International (CC BY-NC-ND 4.0). You must give appropriate credit to authors and reference this article if parts of the article are reproduced in any manner. Applicable licensing terms are at https://creativecommons.org/licenses/by-nc$\mathrm{nd} / 4.0 \%$ 


\title{
Synthesis, Crystal Structure, Hirshfeld Surface, Energy Framework and Molecular Docking of 2-(((6-Methoxy Pyridin-3-YI)Imino)Methyl)Phenol
}

\author{
M. Singh ${ }^{\alpha}$, S. Anthal ${ }^{\sigma}$, P. Akhileshwari ${ }^{\rho}$, M. A. Sridhar ${ }^{\omega}, H . M$. Vinusha ${ }^{\ddagger}$, S. Bindya ${ }^{\S}$, M. Begum ${ }^{x}$, \\ R. K. Chandrasekaran ${ }^{\vee}$, M. Saminathan ${ }^{\ominus}$ \& R. Kant ${ }^{\zeta}$
}

Abstract- The structure of 2-((6-methoxypyridin-3yl)imino)methyl)phenol (MPIMP) $\left(\mathrm{C}_{13} \mathrm{H}_{12} \mathrm{~N}_{2} \mathrm{O}_{2}\right)$ has been determined by $\mathrm{X}$-ray diffraction methods. It crystallizes in the tetragonal crystal system with space group $\mathrm{P}_{2} / \mathrm{n}$ and unit cell dimensions $a=14.2958(3) \AA, b=14.2958(3) \quad \AA$, $c=11.0179(3) \AA, V=2251.73(12) \AA^{3}, Z=8$. The structure has been refined by full-matrix least square procedure to a final R-value of $0.0518\left(w R_{2}=0.1312\right)$ for 1709 observed reflections. The molecules linked via two intermolecular (C$\mathrm{H}$...N and $\mathrm{C}-\mathrm{H} . . . \mathrm{O}$ ) hydrogen bonds. The crystal structure was further stabilized by a strong intramolecular $\mathrm{N}-\mathrm{H}$...O hydrogen bond. The Hirshfeld surface analysis reveals the interaction contacts of the molecule and the strength of molecular packing in the crystal. The energy framework has been performed through different intermolecular interaction energies for structural stability. The molecular docking of MPIMP was performed against tuberculosis enzyme Decaprenylphosphoryl-b-Dribose 20-epimerase (DprE1, PDB code: $4 \mathrm{KW5}$ ) to reconnoiter the binding interactions at the active sites.

Keywords: crystal structure, x-ray diffraction, direct methods, intermolecular interactions, and molecular docking.

\section{InTRODUCTION}

T he pyridine Schiff bases form one of the most significant classes of chemical compounds in organic chemistry and are generally characterized by the presence of pyridine and a phenolic ring connected by an azomethine group. The nitrogen present in the pyridine is usually responsible for the antifungal effects, while the phenolic ring participates in the bioactivity [1]. Schiff bases, being synthetically available and structurally varied, are obtained by replacing the carbonyl group $(>\mathrm{C}=\mathrm{O})$ present in the

Author $\alpha \sigma$ క: X-ray Crystallography Laboratory, Department of Physics, University of Jammu, Jammu -180006, India.

e-mail: rkant.ju@gmail.com

Author $\rho \omega$ : Department of Studies in Physics, University of Mysore, Manasagangotri, Mysore 570 006, Karnataka, India.

Author $¥ \S \chi$ : Department of Chemistry, Sri Jayachamarjendra College of Engineering, JSS Science and Technology University, JSS Technical Institutional Campus, Mysuru, Karnataka 570 006, India.

Author v: Department of Physics, Thanthai Periyar EVR Government Polytechnic College, Vellore, Tamil Nadu, India.

Author $\theta$ : Department of Physics, Thanthai Periyar Government Institute of Technology, Vellore, Tamil Nadu, India. aldehyde or ketone with imine or azomethine group $(>\mathrm{C}=\mathrm{N})$ by reacting the carbonyl group with primary amines $\left(-\mathrm{NH}_{2}\right)$ [2].

As the Schiff bases with an imine group in its structure exhibit a wide range of potential for biological activities like antifungal, antibacterial, anticancer, antidepressant, anticonvulsant, anti-inflammatory, antiviral, antitumor, antioxidant, etc. [3-15], we present synthesis and single crystal X-ray (SCXR) structure and related spectroscopic characterization of a new pyridine Schiff base MPIMP. The SCXR molecular structure has been obtained by using direct methods, and Hirshfeld surfaces $(\mathrm{HS})$ and Energy framework calculations have been performed by using Crystal Explorer (17.5) [16]. Since pyridine derivatives are capable of inhibiting Decaprenylphosphoryl-b-Dribose 20-epimerase (DprE1) $[17,18]$, in silico molecular docking of MPIMP has also been reported.

\section{il. Experimental Section}

All the chemicals of analytical grade required for our present research work were purchased from Sigma Aldrich and utilized without any purification.

The Schiff base, 2-(((6-methoxypyridin-3yl)imino)methyl)phenol has been synthesized by condensation reaction between 6-methoxypyridin-3amine with 2-hydroxybenzaldehyde. 6-methoxypyridin-3amine $(1.24 \mathrm{~g}, 0.01 \mathrm{~mol})$ has been mixed with 2hydroxybenzaldehyde $(1.22 \mathrm{~g}, 0.01 \mathrm{~mol})$ and $10 \mathrm{ml}$ of methanol as solvent. The mixture was refluxed with 2-3 drops of glacial acetic acid at $60-70^{\circ} \mathrm{C}$ for $6 \mathrm{hrs}$. The reaction progress was monitored by using TLC. The reaction mixture kept for overnight evaporation after the completion of the reaction. The reddish-brown colored crystals have been recrystallized using methanol. The Reaction scheme of the compound is presented in Fig. 1.

The intensity data of MPIMP were collected using Super Nova, Single source at offset/far, HyPix3000 diffractometer equipped with graphite monochromatic $\mathrm{MoK}_{\alpha}$ radiation $(\lambda=0.71073 \AA)$. Using Olex2 [19], the structure was solved using SHELXT [20] software routine with Intrinsic Phasing. Five cycles of full-matrix leastsquares refinement have been performed, and the final

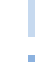


R-factor (0.0518) yielded the best possible atomic peaks. All non-hydrogen atoms of the molecule were located from the E-map and refined in anisotropic approximation using SHELXL [21]. The Crystallographic data are summarized in Table I. Hydrogen atoms bonded to $\mathrm{C}$ atoms were geometrically fixed and allowed to ride on the corresponding non- $\mathrm{H}$ atoms $[\mathrm{C}-\mathrm{H}$ $=0.93-0.96 \AA$, and $U_{\text {iso }}(H)=1.5 U_{\text {eq }}$ of the attached $\mathrm{C}$ atoms for methyl groups and $1.2 \mathrm{U}_{\text {eq }}(\mathrm{C})$ for other $\mathrm{H}$ atoms]. Residual electron density ranges from -0.27 to $0.15 e . \AA^{-3}$. The atomic scattering factors were taken from the International Tables for X-ray Crystallography (1992, Vol C, Tables 4.2.6.8 and 6.1.1.4). Olex2 [19], PLATON [22], PARST [23], and Mercury [24] defines the molecular geometry. The crystallographic information file

(CIF) of the compound has been deposited at Cambridge Crystallographic Data centre (CCDC number 2091399). This CIF file can be accessed free of cost from Cambridge Crystallographic Data Center via https://www.ccdc.cam.ac.uk/structures.

The Hirshfeld surface $(H S)$ mapped plots $\left(d_{n o r m}\right.$, 2-D fingerprint, electrostatic potential, shape-index, and curvedness) and energy framework has been generated using Crystal-Explorer (version 17.5) with B3LYP function and 6-31G (d, p) basic set [16]. The atomic coordinates have been imported from the final validated CIF to Crystal Explorer (17.5). HS has been drawn for the asymmetric unit using high resolution of threedimensional pictures of intermolecular close contacts in a crystal.

The molecular docking studies have been executed using AutoDock Vina software [25] which is a suite of automated docking tools (ADT). The target enzyme Decaprenylphosphoryl-b-Dribose 20-epimerase (4KW5) has been obtained from the protein data bank (www.rcsb.org/pdb). The coordinates of the grid center are fixed at $X=6.47, Y=-8.61, Z=39.07$, and grid sphere radius is 42 . The conformational protein structure is modeled and visualized using Discovery Studio Visualizer [26].

\section{ili. Result and Discussion}

The X-ray crystallographic analysis of MPIMP reveals its asymmetric unit consists of a benzene and pyridine ring. An ORTEP plot of the molecular structure is shown in Fig. 2 [24]. The bond distances, bond angles, and torsion angles between the non- $\mathrm{H}$ atoms are contained in Table II. All the bond distances and bond angles are within the normal range and are comparable with the related structures [27-28]. A C $=\mathrm{N}$ group seems to have a strong electron-withdrawing character in the azomethine group of the structure. Thus, the $\mathrm{C} 1-\mathrm{O} 1$ bond distance of $1.3490(17) \AA$ is reliable with $\mathrm{C}-\mathrm{O}$ single bond length; similarly, the $\mathrm{C} 7=\mathrm{N} 1$ distance of $1.2834(16)$ agrees well with the standard value [28]. The benzene and pyridine ring systems [having a dihedral angle of $7.53(5)^{\circ}$ ] are planar.

In the crystal structure, strong $\mathrm{N}-\mathrm{H} \ldots \mathrm{O}$ intramolecular interactions are responsible for the stability of molecules within the unit cell. This intramolecular interaction leads to the formation of a virtual six-membered ring forming the S6 graph set motif [29]. In the crystal structure, there exist two intermolecular hydrogen bonds $[\mathrm{C} 7-\mathrm{H} 7 \ldots \mathrm{N} 2$ and $\mathrm{C} 13-$ $\mathrm{H} 13 \mathrm{~A} \ldots \mathrm{.}$. 1] that link the molecules into chains along the c-axis, as shown in Fig. 3 (Mercury) [24]. A summary of intra and inter-molecular hydrogen bonding are listed in Table III. The packing of molecules in the crystal viewed along the c-axis is visualized in Fig. 4, (PLATON) [22].

Hirshfeld surface (HS) analysis was carried out to explore the intermolecular interactions responsible for molecular packing in the crystal. Fig. 5(a) shows the 2D fingerprint plot of overall contribution from all the interactions to the total HS area, whereas Fig.5 $\left(\mathrm{a}^{*}\right)$ represents the HS over normalized contact distance $d_{\text {norm }}$; where $d_{\text {norm }}$ gives the distance between two atoms across the surface to the combined van der Waals radii of the atoms [30]. The $d_{\text {norm }}$ value is either positive or negative, depending upon the longer or shorter intermolecular contacts than the van de Waals radii, respectively. The red-colored region represents shorter contacts with negative $d_{\text {norm }}$ value, blue regions correspond to longer contacts with positive $d_{\text {norm }}$ value, and the white region represent the distance of contacts is exactly equal to the van der Waals separation with a $d_{\text {norm }}$ value of zero [31]. The three red spots shown on the HS represent the shortest hydrogen bond interactions due to strong $\mathrm{C}-\mathrm{H} \ldots \mathrm{O}, \mathrm{C}-\mathrm{H} \ldots \mathrm{N}$, and $\mathrm{O}-$ $\mathrm{H}$...N contacts shorter than van der Waals radii as shown in Fig. 5( $\left.a^{*}\right)$.

Fig. 5(b-f) represents the 2D fingerprint plots showing $\mathrm{H}-\mathrm{H}, \quad \mathrm{C}-\mathrm{H} / \mathrm{H}-\mathrm{C}, \quad \mathrm{O}-\mathrm{H} / \mathrm{H}-\mathrm{O}, \quad \mathrm{C}-\mathrm{C}, \quad \mathrm{N}-\mathrm{H} / \mathrm{H}-\mathrm{N}$ contacts with the percentages contribution and $\left(\mathrm{b}^{\star}\right)$, $\left(c^{\star}\right),\left(d^{\star}\right),\left(e^{\star}\right),\left(f^{\star}\right)$ represents the associated $d_{\text {norm }} H S$, respectively. These plots have been generated in the $\mathrm{d}_{\text {norm }}$ range $-0.1466 \AA$ to $1.7068 \AA$. The $d_{i}$ and $d_{e}$ on the plot are the distance from the HS to the nearest nuclei inside and outside the surface, respectively. For any given $d_{i}$ and $d_{e}$ pairs on the 2D plot, white color represents no occurrence, blue color shows some occurrence, and green indicates more frequent occurrence. These 2D fingerprint plots enable us to determine the percentage contribution of each type of contact to the total HS area. The major contribution to the total Hireshfeld area is $\mathrm{H}-\mathrm{H}$ contacts with $50.9 \%$, while the remaining significant contribution is from C$\mathrm{H} / \mathrm{H}-\mathrm{C}(17.1 \%), \mathrm{O}-\mathrm{H} / \mathrm{H}-\mathrm{O}(12.8 \%), \mathrm{C}-\mathrm{C}(6.2 \%)$, and $\mathrm{N}-$ $\mathrm{H} / \mathrm{H}-\mathrm{N}(5.8 \%)$, as shown in Fig. 6. The $\mathrm{d}_{i}$ and $\mathrm{d}_{\mathrm{e}}$ combination in the $2 \mathrm{D}$ fingerprint plot provides an outline of intermolecular contacts in the crystal, where one molecule acts as an acceptor $\left(d_{e}<d_{i}\right)$ and the other as a donor $\left(d_{e}>d_{i}\right)$. The $\mathrm{O} \ldots \mathrm{H} / \mathrm{H} \ldots \mathrm{O}$ and 
$\mathrm{N} \ldots \mathrm{H} / \mathrm{H} \ldots \mathrm{N}$ molecular interactions represent by two distinct spikes in the bottom left and right region of almost equal length in $2 \mathrm{D}$ plots with $\left(\mathrm{d}_{\mathrm{i}}+\mathrm{d}_{\mathrm{e}}\right) \approx 2.50 \AA$ and $2.45 \AA$, respectively, as shown in Fig. $5(\mathrm{~d})$ and $5(\mathrm{f})$.

The Hirshfeld surface (HS) mapped over the calculated electrostatic potential for the title compound MPIMP as shown in Fig.7 (a). This mapping gives direct insight into the intermolecular interaction, which is responsible for molecular packing in the crystal [32]. The electrostatic potential map has been generated by using the B3LYP function with 6-31G (d) basis set [16]. The blue-colored area on the map is the electropositive region (i.e., the region around hydrogen bond donor) and the red-colored area is the electronegative region (i.e., the region around hydrogen bond acceptor). The electropositive blue region near $\mathrm{C} 13-\mathrm{H} 13 \mathrm{~A}$ atoms is complementary to the electronegative red region around the $\mathrm{O} 1$ atom, as shown in Fig. 7(a).

Fig. 7(b) shows the molecular HS mapped over the shape index for the compound. This mapping of shape index gives us the visual identification of the regions where the two molecular HS touch each other, and uses complementary pairs of red and blue colored schemes [30]. The concave red-colored region on the shape index represents the cluster of the surface around the acceptor atoms. In contrast, the blue-colored bumps regions represent the cluster of the surface around the donor atoms.

The curvedness map displays large regions of green (relatively flat) separated by dark blue boundaries (large positive curvatures), as shown in Fig.7(c). The plot shows no flat surface patches. Consequently, there is no indication of planner stacking between the molecules.

The energy frameworks give information on accurate inter-molecular interaction energies, which are responsible for the supramolecular construction of molecules in the crystal [33]. These calculations has been carried out using the Crystal Explorer (17.5) program based on 6-31G $(d, p)$ basic set [16], where interaction energies have been calculated within a radius of $3.8 \AA$ cluster around a single molecule of the title compound MPIMP. The scale factors used for the construction of energy framework for B3LYP/6-31G (d, p) electron densities are $\mathrm{k}_{-}$ele $=1.057, \mathrm{k} \_\mathrm{pol}=0.740$, $\mathrm{k}$ disp $=0.871$, $\mathrm{k}$ rep $=0.618$ [34], respectively. Table IV contains the interaction energies, viz. electrostatic, polarization, dispersion, and repulsive energies. Fig. 8 represents the molecular pairs in which few molecules are separated by respective radial distance (as shown in Table IV) from the centroid molecule involved in the calculation of interaction energies along the c-axis.

The images of different interactions energies coulomb interaction energy (red), dispersion energy (green), and total energy (blue) of the title compound MPIMP along a, b, and c-axes are illustrated in Fig. 9. The cylinders represent the energies between the molecular pairs joining with the center of mass of the molecules, and the radius of the cylinder is proportional to the magnitude of the interaction energy. The framework of the cylinders represents the relative strengths of molecular packing in different directions. An overall scale factor is applied to expand or contract the size of the cylinders in the framework [33]. To avoid very crowded structures, weaker interactions have been omitted below a certain threshold energy, due to which there is an absence of the cylinders in a particular direction. The calculated energies for electrostatic, polarization, dispersion, and repulsion are $-34.5 \mathrm{KJ} / \mathrm{mol}$, $-8.5 \mathrm{KJ} / \mathrm{mol},-170.1 \mathrm{KJ} / \mathrm{mol}$, and $94.9 \mathrm{KJ} / \mathrm{mol}$, respectively. The total interaction energy is -132.5 $\mathrm{KJ} / \mathrm{mol}$. The dispersion energy dominates over the electrostatics Coulomb energy in the title compound MPIMP.

The molecular docking has done performed against DprE1(PDB code: 4KW5), and its resolve is to calculate the binding modalities of MPIMP. Since the hydrogen bond is an essential key factor in the structure and function of biological compounds, the ligandreceptor interactions have been inspected based on the hydrogen bonding. The molecular binding site of compound MPIMP and pyrazinamide interaction into DprE1 enzyme is present in Fig.10. The binding energy, distance and bonding type of compound MPIMP, and standard drug pyrazinamide with DprE1are listed in Table V. In Compound MPIMP-4KW5 complex, the oxygen (O) atom of MPIMP has branched $\mathrm{H}$-bond polar interaction with the atom NE2 and OE1 of residue HIS123 and GLN336 at a distance 2.506 and $2.204 \AA$, respectively. Moreover, the oxygen atom of MPIMP interacts with atom HZ1 of LYS418 at a separation of $2.530 \AA$. Three hydrophobic Alkyl- $\pi$ interactions can be noticed between atoms of residue (CYS387, VAL365 \& PRO116) and rings of compound MPIMP.

In Pyrazinamide -4KW5 complex, the oxygen (O) atom of pyrazinamide has interaction with the atom $\mathrm{O}$ of residue ALA53 at a distance of $2.027 \AA$, and the hydrogen $(H)$ atom of pyrazinamide has interaction with the atom N of residue GLY55 at a distance of $2.262 \AA$. Moreover, the ring of pyrazinamide Hydrophobic interacts with atom N of GLY125 and atom CD of ALA128 at a separation of 3.800 and $4.847 \AA$, respectively. The outcome predicts that the compound MPIMP could strongly fix in the active site of DprE1, with binding energy of $7.4 \mathrm{kcal} / \mathrm{mol}$, compared to 5.4 $\mathrm{kcal} / \mathrm{mol}$ of pyrazinamide.

\section{Conclusions}

2-(((6-methoxypyridin-3-yl)imino)methyl)phenol crystallizes in tetragonal crystal system with $\mathrm{P} 4_{2} / \mathrm{n}$ space group. The crystallographic analysis shows the presence of different inter and intramolecular interactions, which aids the crystal packing. The 
Hirshfeld surface analysis has been carried out to understand the intermolecular interaction contacts and the percentage contribution of each type of contact. The major contribution is from $\mathrm{H}-\mathrm{H}$ contacts with $50.9 \%$. The energy framework has also been carried out to calculate the different interaction energies viz., electrostatic, dispersion, polarization, and repulsion between the molecular pairs in the crystal, where dispersion energy was the dominant value among all the interaction energies. The molecular docking analysis has been performed. The molecular docking results recommend that the compound MPIMP might exhibit strong inhibitory activity against DprE1 enzymes compare to the available pyrazinamide drug. It may result in the development of the new antituberculosis drug.

\section{ACKNOWLEDGMENTS}

Rajni Kant is thankful to the University of Jammu for funding under the RUSA- 2.0 project of the Government of India.

Table l: Crystal data and experimental details

\begin{tabular}{|c|c|}
\hline Empirical formula & $\mathrm{C}_{13} \mathrm{H}_{12} \mathrm{~N}_{2} \mathrm{O}_{2}$ \\
\hline CCDC No. & 2091399 \\
\hline Formula weight & 228.25 \\
\hline Temperature (K) & 293(2) \\
\hline Crystal system & Tetragonal \\
\hline Space group & $\mathrm{P}_{2} / \mathrm{n}$ \\
\hline$a(\AA)$ & 14.2958 (3) \\
\hline b $(\AA)$ & 14.2958 (3) \\
\hline$c(\AA ̊)$ & $11.0179(3)$ \\
\hline$\alpha\left(^{\circ}\right)$ & 90 \\
\hline$\beta\left({ }^{\circ}\right)$ & 90 \\
\hline$\gamma\left({ }^{\circ}\right)$ & 90 \\
\hline Volume $\left(\AA^{3}\right)$ & $2251.73(12)$ \\
\hline Z & 8 \\
\hline$\rho$ calc $\left(\mathrm{g} / \mathrm{cm}^{3}\right)$ & 1.347 \\
\hline$\mu(\mathrm{mm}-1)$ & 0.093 \\
\hline$F(000)$ & 960.0 \\
\hline Crystal size $\left(\mathrm{mm}^{3}\right)$ & $0.12 \times 0.08 \times 0.06$ \\
\hline Radiation & $\operatorname{MoK} \alpha(\lambda=0.71073 \AA)$ \\
\hline $2 \Theta$ range for data collection $\left(^{\circ}\right)$ & 6.794 to 54.774 \\
\hline Index ranges & $-17 \leq h \leq 17,-17 \leq \mathrm{k} \leq 16,-13 \leq \mathrm{I} \leq 14$ \\
\hline Reflections collected & 17000 \\
\hline Independent reflections & $2430[$ Rint $=0.0311$, Rsigma $=0.0227]$ \\
\hline Data / restraints / parameters & 2430/0/156 \\
\hline Goodness-of-fit on $\mathrm{F}^{2}$ & 1.059 \\
\hline Final $R$ indexes $[I \geq 2 \sigma(I)]$ & $\mathrm{R} 1=0.0518, \mathrm{wR} 2=0.1312$ \\
\hline Final $R$ indexes [all data] & $\mathrm{R} 1=0.0723, \mathrm{wR} 2=0.1456$ \\
\hline Largest diff. peak /hole $\left(e . \AA^{-3}\right)$ & $0.15 /-0.27$ \\
\hline
\end{tabular}

Table II: Bond distances $(\AA)$, Bond angles (o) and Torsion angles ( ${ }^{\circ}$ )

\begin{tabular}{c|c|c|c}
\hline \multicolumn{1}{c}{ Bond } & Distance $(\AA)$ & Bond & Distance $(\AA)$ \\
\hline O2-C10 & $1.3454(17)$ & C6-C7 & $1.4401(19)$ \\
O2-C13 & $1.4326(17)$ & C6-C1 & $1.4053(19)$ \\
O1-C1 & $1.3490(17)$ & C6-C5 & $1.3997(19)$ \\
N1-C8 & $1.4122(18)$ & C10-C11 & $1.3934(19)$ \\
N1-C7 & $1.2834(16)$ & C1-C2 & $1.380(2)$ \\
N2-C10 & $1.3130(16)$ & C5-C4 & $1.364(2)$ \\
N2-C9 & $1.3394(17)$ & C12-C11 & $1.3611(19)$ \\
C8-C9 & $1.3715(18)$ & C4-C3 & $1.384(2)$ \\
C8-C12 & $1.3967(18)$ & C3-C2 & $1.377(2)$ \\
\hline Bond & Angles $\left({ }^{\circ}\right)$ & Bond & Angles $\left(^{\circ}\right)$ \\
\hline C10-O2-C13 & $117.21(11)$ & N1-C7-C6 & $122.52(12)$ \\
C7-N1-C8 & $121.51(11)$ & O1-C1-C6 & $120.94(14)$ \\
C10-N2-C9 & $116.74(11)$ & O1-C1-C2 & $119.33(13)$ \\
C9-C8-N1 & $117.25(11)$ & C2-C1-C6 & $119.73(13)$ \\
C9-C8-C12 & $116.60(13)$ & N2-C9-C8 & $125.05(12)$ \\
\hline \multicolumn{4}{|c}{}
\end{tabular}




\begin{tabular}{c|c|c|c}
\hline C12-C8-N1 & $126.14(11)$ & C4-C5-C6 & $121.65(13)$ \\
C1-C6-C7 & $121.97(12)$ & C11-C12-C8 & $119.55(12)$ \\
C5-C6-C7 & $119.82(12)$ & C12-C11-C10 & $118.66(12)$ \\
C5-C6-C1 & $118.21(13)$ & C5-C4-C3 & $119.34(14)$ \\
O2-C10-C11 & $116.88(11)$ & C2-C3-C4 & $120.51(15)$ \\
N2-C10-O2 & $119.74(12)$ & C3-C2-C1 & $120.56(15)$ \\
N2-C10-C11 & $123.38(14)$ & \multicolumn{2}{|c}{ Torsion Angles ( $)$} \\
\hline Bond & Torsion Angles ( $\left.{ }^{\circ}\right)$ & $0.86(21)$ \\
C13-O2-C10-N2 & $-2.66(19)$ & C7-C6-C1-O1 & $-178.90(14)$ \\
C13-O2-C10-C11 & $176.99(13)$ & C7-C6-C1-C2 & $-179.45(13)$ \\
C7-N1-C8-C9 & $172.36(13)$ & C5-C6-C1-O1 & $0.79(21)$ \\
C7-N1-C8-C12 & $-8.87(20)$ & C5-C6-C1-C2 & $178.79(14)$ \\
C8-N1-C7-C6 & $178.37(12)$ & C7-C6-C5-C4 & $-0.91(21)$ \\
C9-N2-C10-O2 & $179.26(12)$ & C1-C6-C5-C4 & $-178.76(13)$ \\
C9-N2-C10-C11 & $-0.36(20)$ & O2-C10-C11-C12 & $0.88(22)$ \\
C10-N2-C9-C8 & $-0.57(21)$ & N2-C10-C11-C12 & $-179.97(14)$ \\
N1-C8-C9-N2 & $179.81(13)$ & O1-C1-C2-C3 & $-0.21(23)$ \\
C12-C8-C9-N2 & $0.92(21)$ & C6-C1-C2-C3 & $0.43(23)$ \\
N1-C8-C12-C11 & $-179.12(13)$ & C6-C5-C4-C3 & $-0.48(21)$ \\
C9-C8-C12-C11 & $-0.34(20)$ & C8-C12-C11-C10 & $0.19(24)$ \\
C1-C6-C7-N1 & $1.94(21)$ & C5-C4-C3-C2 & $-0.29(25)$ \\
C5-C6-C7-N1 & $-177.75(13)$ & C4-C3-C2-C1 & \\
\hline
\end{tabular}

Table III: Hydrogen bonding geometry (e.s.d.'s in parentheses)

\begin{tabular}{c|c|c|c|c}
\hline $\mathrm{D}-\mathrm{H} \ldots \mathrm{A}$ & $\mathrm{D}-\mathrm{H}(\AA)$ & $\mathrm{H} \ldots \mathrm{A}(\AA)$ & $\mathrm{D} \ldots \mathrm{A}(\AA)$ & $\mathrm{D}-\mathrm{H} \ldots \mathrm{A}\left({ }^{\circ}\right)$ \\
\hline $\mathrm{O} 1-\mathrm{H} 1 \ldots \mathrm{N} 1$ & 0.82 & 1.88 & $2.6137(15)$ & 148 \\
$\mathrm{C} 7-\mathrm{H} 7 \ldots \mathrm{N} 2^{(i)}$ & 0.93 & 2.57 & $3.4273(17)$ & 153 \\
$\mathrm{C} 13-\mathrm{H} 13 \mathrm{~A} \ldots 1^{(i)}$ & 0.96 & 2.58 & $3.384(2)$ & 141 \\
\hline
\end{tabular}

Symmetry codes:

(i) $1 / 2-x, 3 / 2-y, z$ (ii) $1-x,-1 / 2+y, 1 / 2+z$

Table IV: Different interaction energies of the molecular pairs in $\mathrm{KJ} / \mathrm{mol}$.

\begin{tabular}{|c|c|c|c|c|c|c|c|c|}
\hline $\mathrm{N}$ & $\begin{array}{l}\text { Symmetry } \\
\text { operation }\end{array}$ & $\begin{array}{c}\text { Radial } \\
\text { Distance }\end{array}$ & $\begin{array}{l}\text { Electron } \\
\text { Density }\end{array}$ & E_ele & E_pol & E_dis & E_rep & E_tot \\
\hline 1 & $\begin{array}{l}-x+1 / 2,- \\
y+1 / 2, z\end{array}$ & 4.46 & $\begin{array}{l}\text { B3LYP/6- } \\
31 G(d, p)\end{array}$ & -7.7 & -2.0 & -54.8 & 28.5 & -39.8 \\
\hline 1 & $-x,-y,-z$ & 5.77 & $\begin{array}{l}\text { B3LYP/6- } \\
31 G(d, p)\end{array}$ & -5.7 & -1.5 & -48.3 & 19.7 & -37.0 \\
\hline 2 & $\begin{array}{c}-y+1 / 2, x,- \\
z+1 / 2\end{array}$ & 9.32 & $\begin{array}{l}\text { B3LYP/6- } \\
31 G(d, p)\end{array}$ & -4.5 & -0.6 & -10.4 & 6.1 & -10.5 \\
\hline 1 & $-x,-y,-z$ & 10.34 & $\begin{array}{l}\text { B3LYP/6- } \\
31 G(d, p)\end{array}$ & -0.6 & -0.3 & -17.8 & 8.1 & -11.3 \\
\hline 2 & $\begin{array}{c}y+1 / 2,-x \\
z+1 / 2\end{array}$ & 6.35 & $\begin{array}{l}\text { B3LYP/6- } \\
31 G(d, p)\end{array}$ & -14.2 & -3.1 & -24.1 & 24.3 & -23.3 \\
\hline 2 & $\begin{array}{c}-y, x+1 / 2 \\
z+1 / 2\end{array}$ & 6.35 & $\begin{array}{l}\text { B3LYP/6- } \\
31 G(d, p)\end{array}$ & -1.8 & -1.0 & -14.7 & 7.7 & -10.6 \\
\hline
\end{tabular}


Table V: Binding energy, hydrogen bond and hydrophobic contacts of 2-Methoxy 4-(2-hydroxybenzylidene) amino pyridine (MPIMP) and pyrazinamide with 4WK5.

\begin{tabular}{|c|c|c|c|c|c|c|c|}
\hline Inhibitor & $\begin{array}{l}\text { Binding } \\
\text { Energy } \\
\left(\text { Kcal m}^{-1}\right) \\
\end{array}$ & Interactions & $\begin{array}{c}\text { Distance } \\
\AA\end{array}$ & Bonding & $\begin{array}{l}\text { Bonding } \\
\text { Types }\end{array}$ & $\begin{array}{l}\text { Binding } \\
\text { Site of } \\
\text { Protein }\end{array}$ & $\begin{array}{l}\text { Binding Site } \\
\text { of Ligand }\end{array}$ \\
\hline MPIMP & 7.4 & 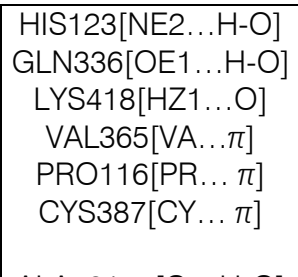 & $\begin{array}{l}2.506 \\
2.204 \\
2.530 \\
4.833 \\
5.445 \\
5.019\end{array}$ & $\begin{array}{l}\text { Hydrogen } \\
\text { Hydrogen } \\
\text { Hydrogen } \\
\text { Hydrophobic } \\
\text { Hydrophobic } \\
\text { Hydrophobic }\end{array}$ & $\begin{array}{l}\text { H-bond } \\
\text { H-bond } \\
\text { H-bond } \\
\text { Alkyl- } \pi \\
\text { Alkyl- } \pi \\
\text { Alkyl- } \pi\end{array}$ & $\begin{array}{l}\text { NE2 } \\
\text { OE1 } \\
\text { HZ1 } \\
\text { VA } \\
\text { PR } \\
\text { CY }\end{array}$ & \begin{tabular}{|c|}
0 \\
$O$ \\
$O$ \\
Methoxy ring \\
Pyridine ring \\
Methoxy \\
Ring
\end{tabular} \\
\hline $\begin{array}{c}\text { pyrazinamid } \\
e\end{array}$ & 5.4 & $\begin{array}{c}\text { ALA53144[O...H-O] } \\
\text { GLY55[N-H... }] \\
\text { GLY125[N.... }] \\
\text { ALA128[CD ... }] \\
\end{array}$ & $\begin{array}{l}2.027 \\
2.262 \\
3.800 \\
4.847 \\
\end{array}$ & $\begin{array}{c}\text { Hydrogen } \\
\text { Hydrogen } \\
\text { Hydrophobic } \\
\text { Hydrophobic } \\
\end{array}$ & $\begin{array}{l}\text { H-bond } \\
\text { H-bong } \\
\text { Amide- } \pi \\
\text { Alkyl- } \pi \\
\end{array}$ & $\begin{array}{l}\mathrm{O} \\
\mathrm{N} \\
\mathrm{N} \\
\mathrm{CD}\end{array}$ & $\begin{array}{l}\text { O } \\
\text { O } \\
\text { Ring } \\
\text { Ring } \\
\end{array}$ \\
\hline
\end{tabular}

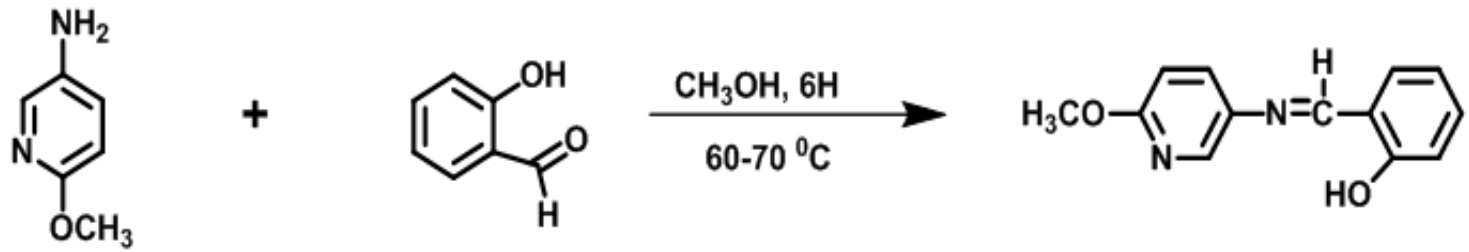

\section{6-methoxypyridin-3-amine 2-hydroxybenzaldehyde}

2-(((6-methoxypyridin-3-yl)imino)methyl)phenol

Fig. 1: Reaction scheme of 2-(((6-methoxypyridin-3-yl)imino)methyl)phenol.

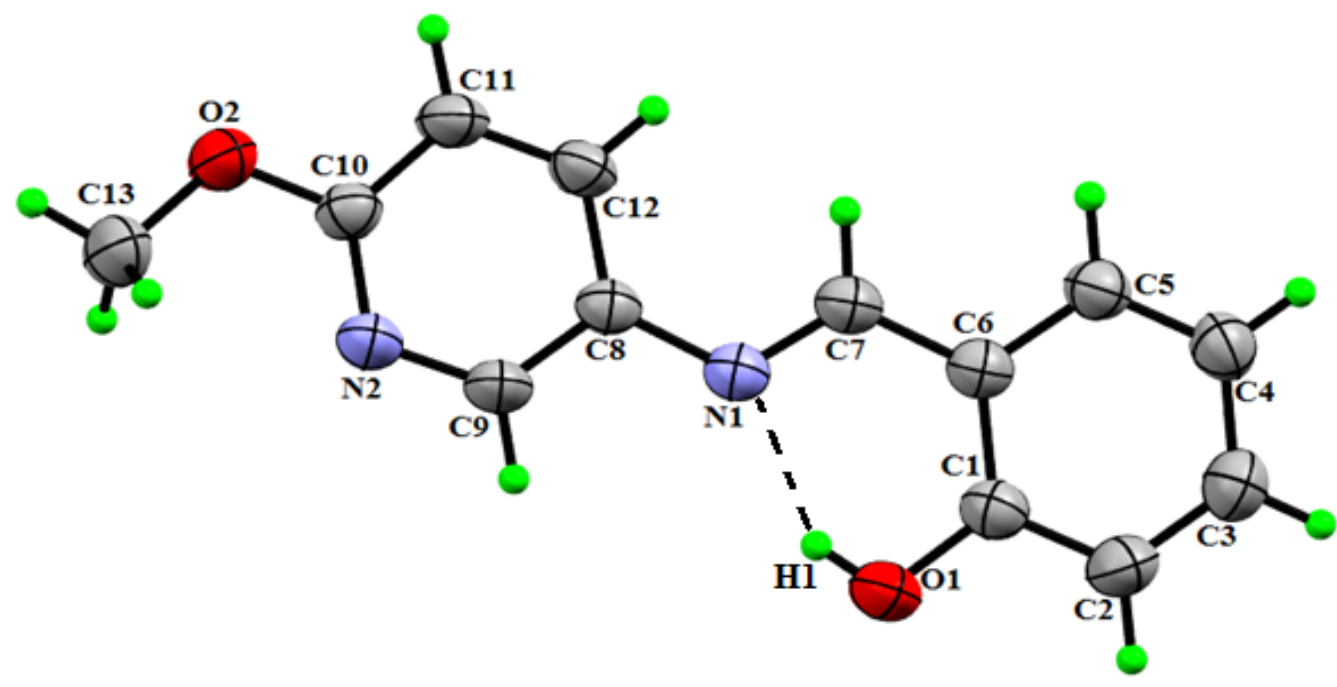

Fig. 2: ORTEP view of molecule with displacement ellipsoids drawn at $40 \%$ probability level $(\mathrm{H}$ atoms are shown as small arbitrary radius). The dotted line shows the intramolecular hydrogen bond. 


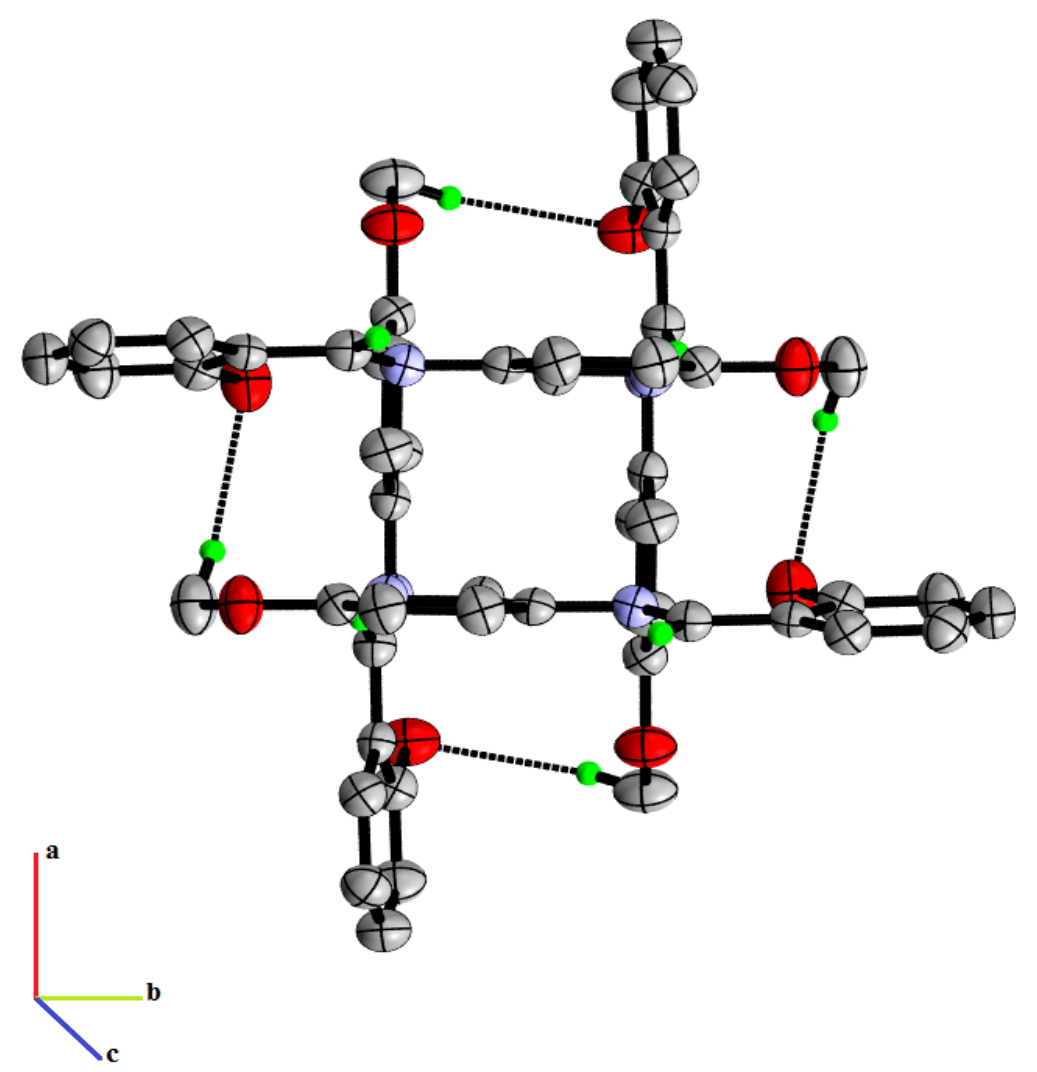

Fig. 3: Packing of crystal structure view along c-axis (dashed lines represents $\mathrm{H}$-bonded interactions)

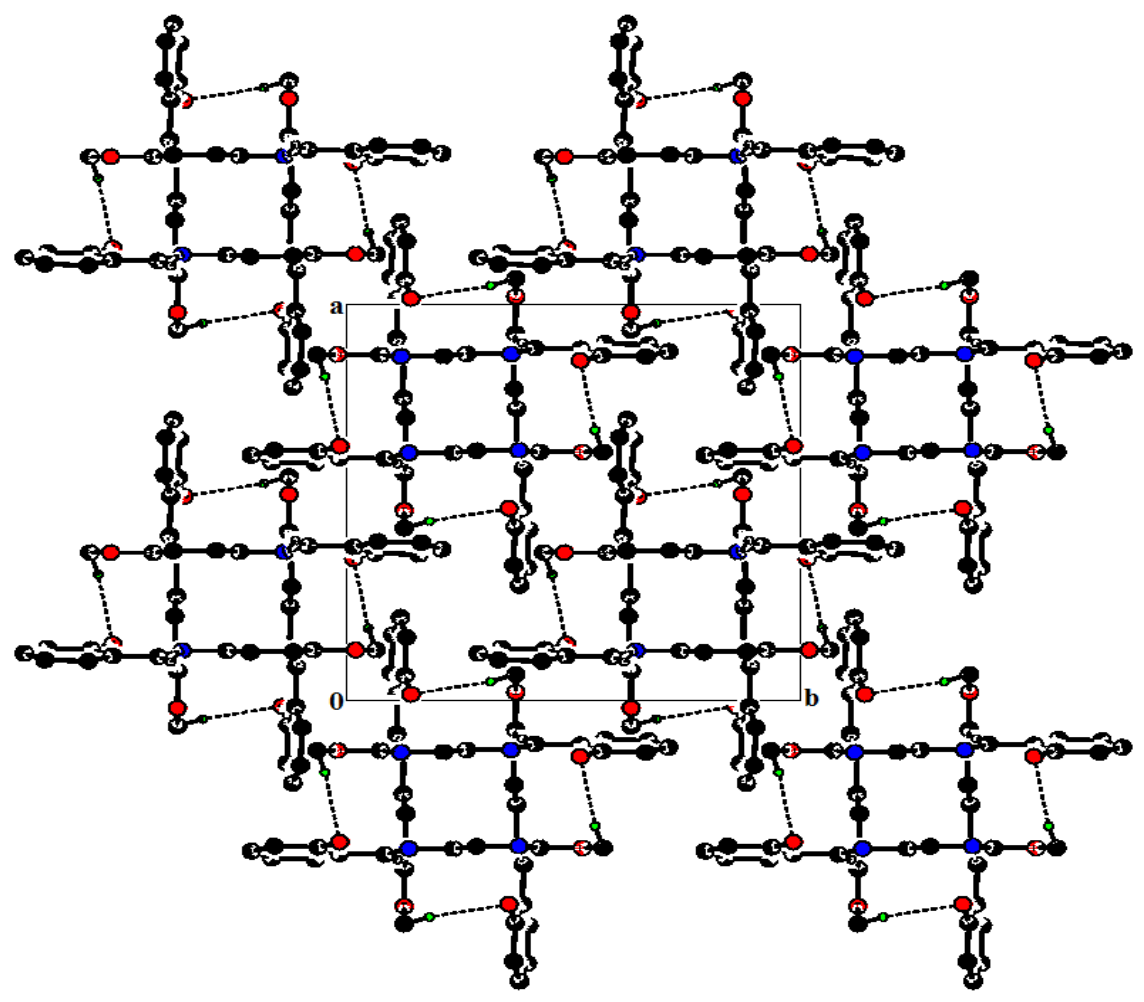

Fig. 4: Packing of crystal structure view along c-axis (dashed lines represents H-bonded interactions). 


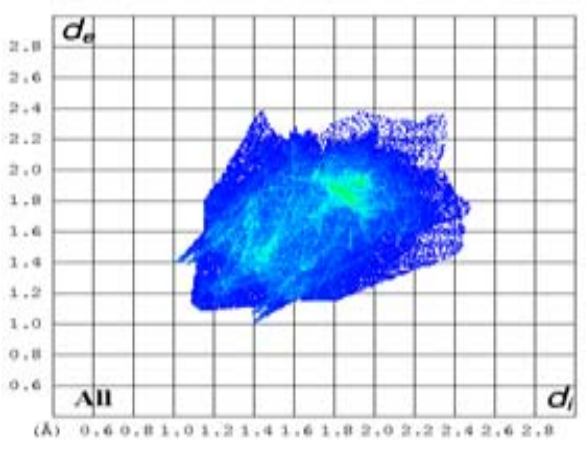

(a)

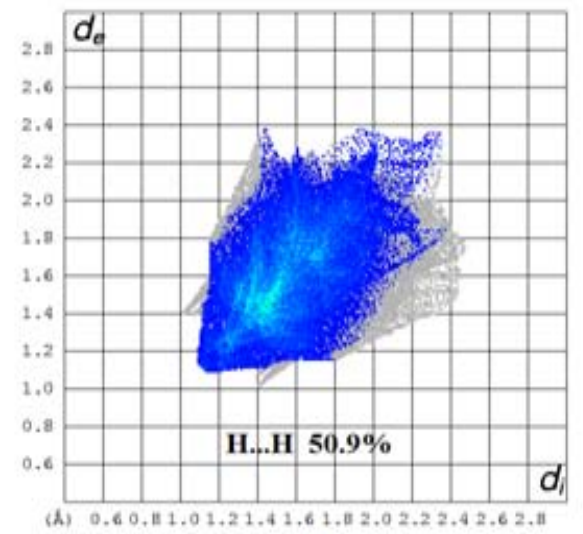

(b)

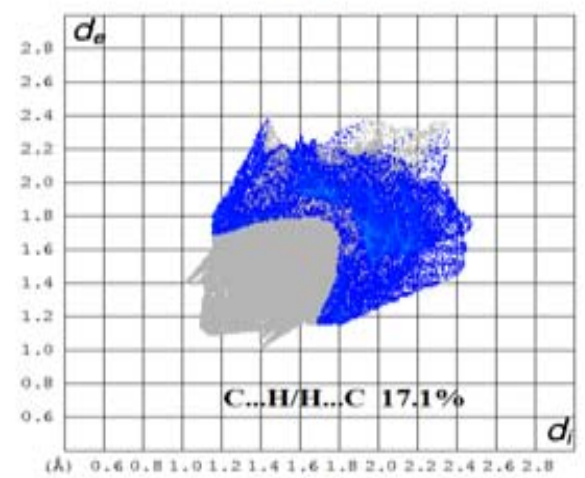

(c)

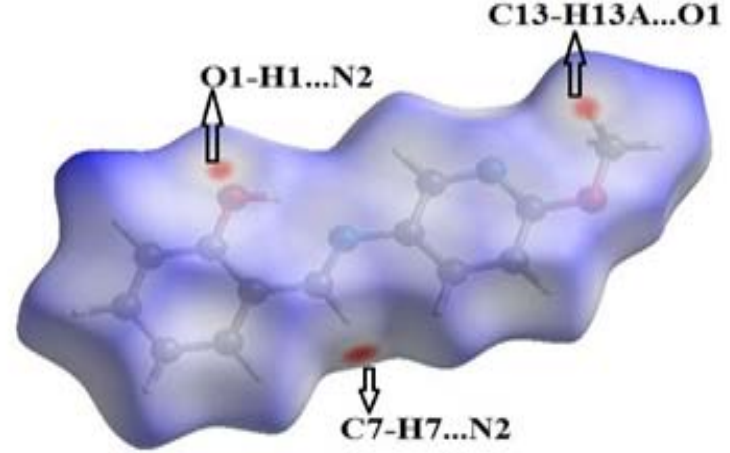

(a*)

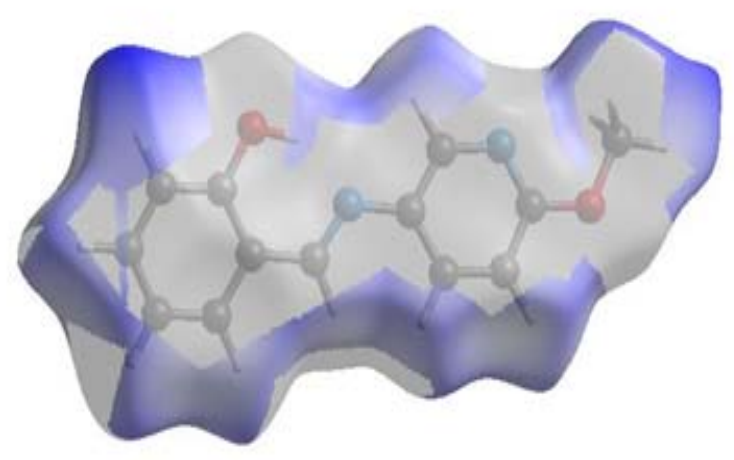

(b*)

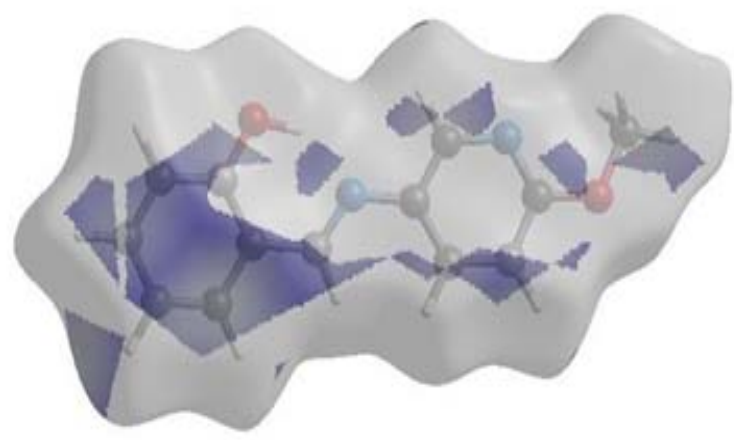

$\left(c^{*}\right)$ 


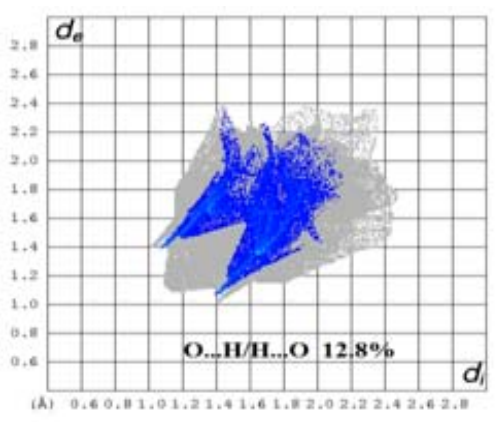

(d)

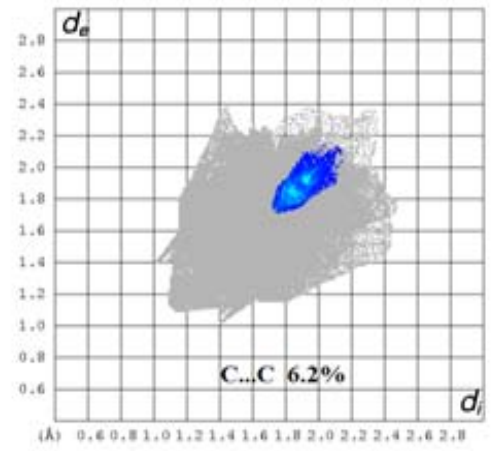

(e)

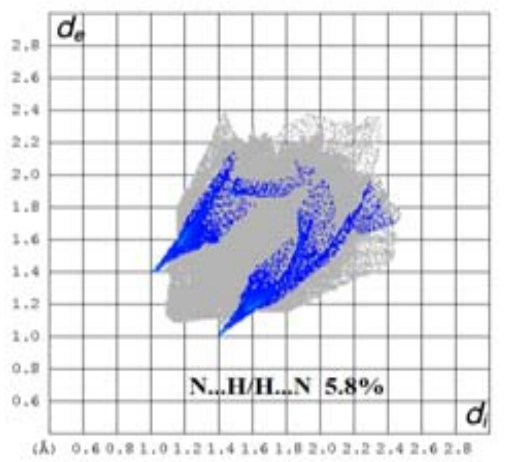

(f)

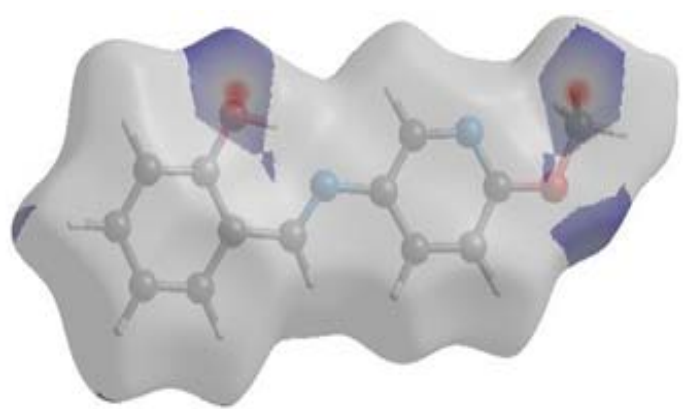

$\left(\mathrm{d}^{*}\right)$

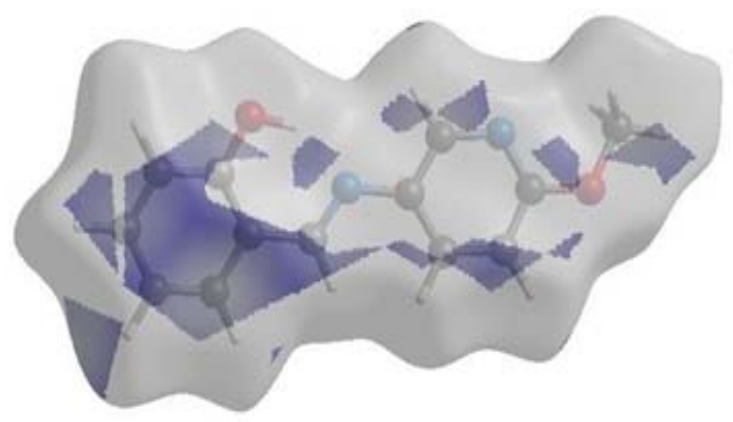

$\left(\mathrm{e}^{*}\right)$

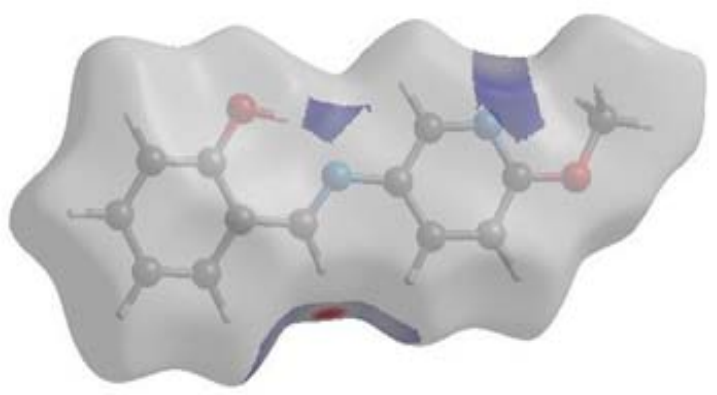

$\left(\mathrm{f}^{*}\right)$

Fig. 5: Fingerprint plots of the compound from all the intermolecular contacts, $\left(\mathrm{a}^{\star}\right)$ Hireshfeld surface mapped over $\mathrm{d}_{\text {norm }}$, (b), (c), (d), (e) and (f) are the $2 \mathrm{D}$ fingerprint plots showing $\mathrm{H}-\mathrm{H}, \mathrm{C}-\mathrm{H} / \mathrm{H}-\mathrm{C}, \mathrm{O}-\mathrm{H} / \mathrm{H}-\mathrm{O}, \mathrm{C}-\mathrm{C}, \mathrm{N}-\mathrm{H} / \mathrm{H}-\mathrm{N}$ contacts with the percentages contribution and $\left(b^{\star}\right),\left(c^{*}\right),\left(d^{\star}\right),\left(e^{\star}\right)$ and $\left(f^{*}\right)$ represent the associated $d_{\text {norm }}$ Hireshfeld surfaces respectively 


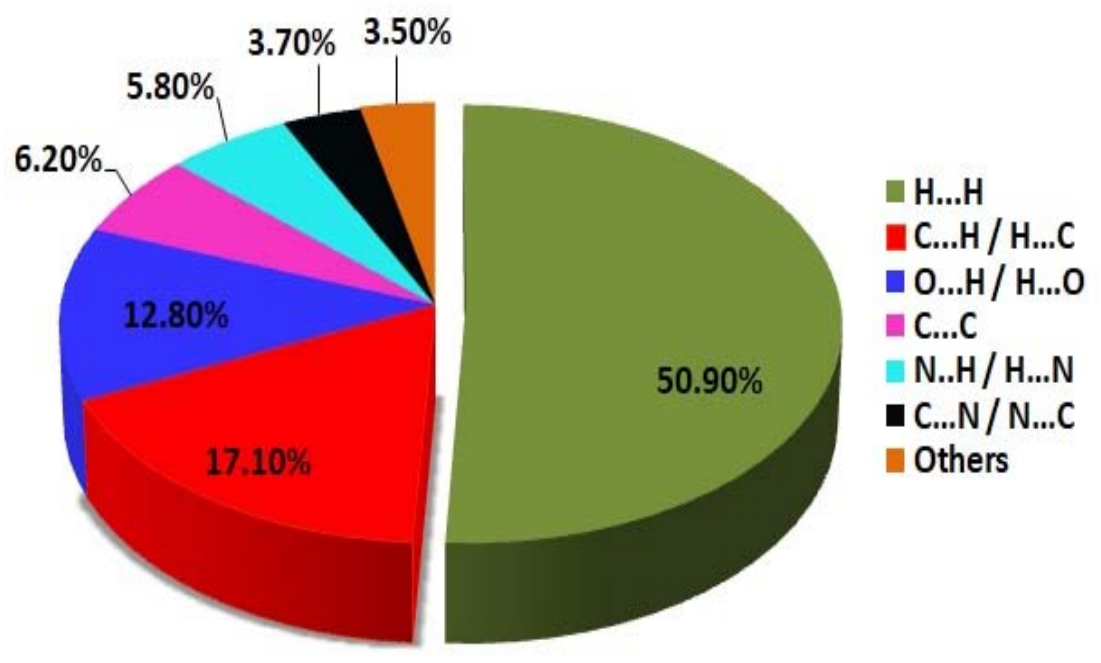

Fig. 6: Relative contributions of various intermolecular interactions to the Hirshfeld surface area.

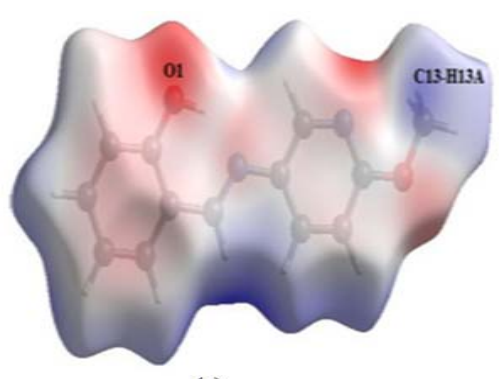

(a)

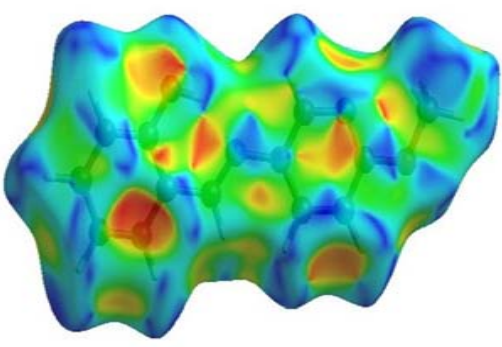

(b)

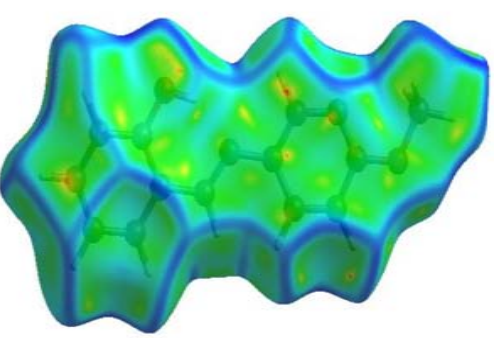

(c)

Fig. 7.(a): Electrostatic potential map (b) Shape index mapped on Hirshfeld surface (c) Curvedness plot mapped on Hirshfeld surface

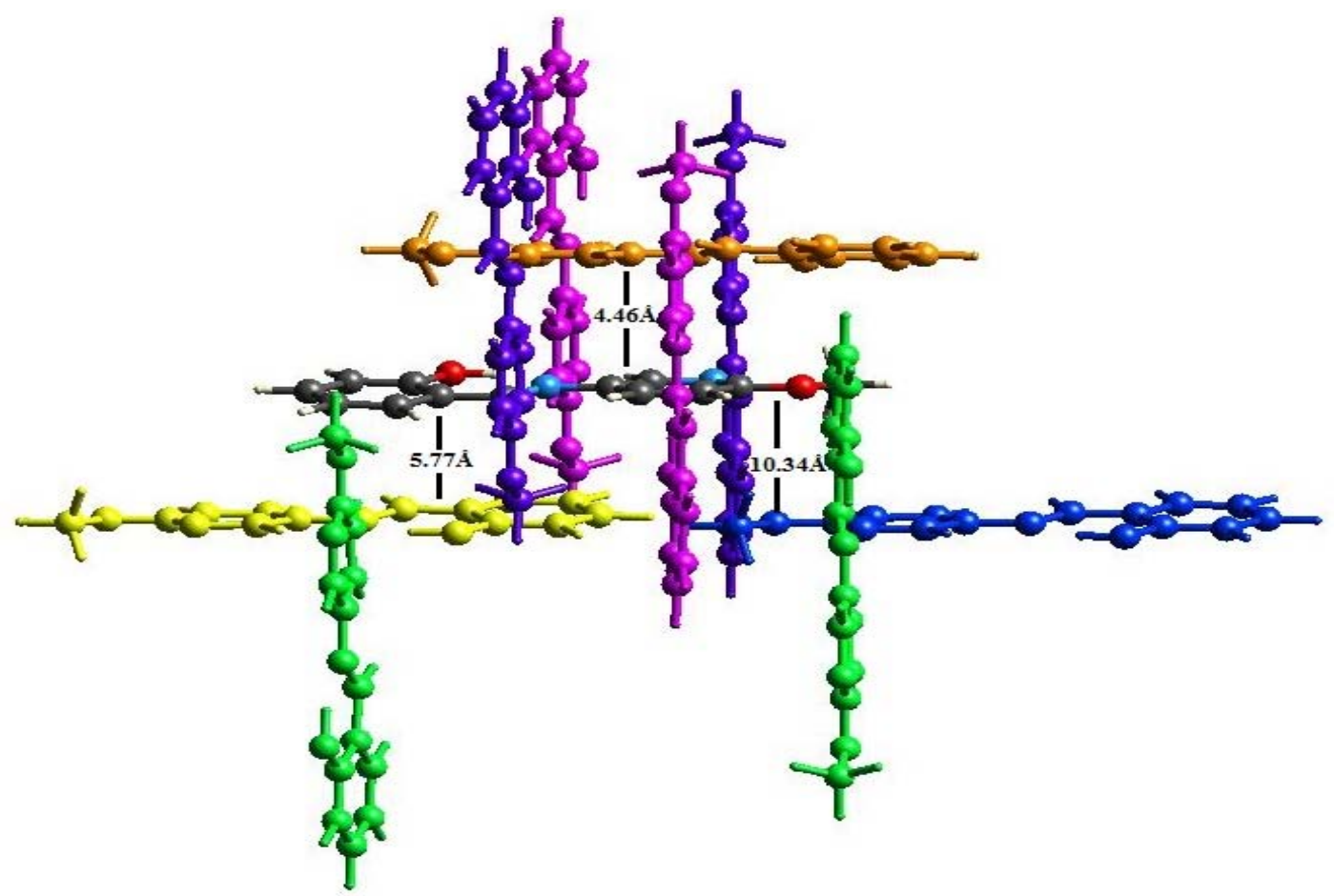

Fig. 8: Molecular pairs separated by respective radial distance from the centriod molecule involved in the calculation of interaction energies along c-axis 

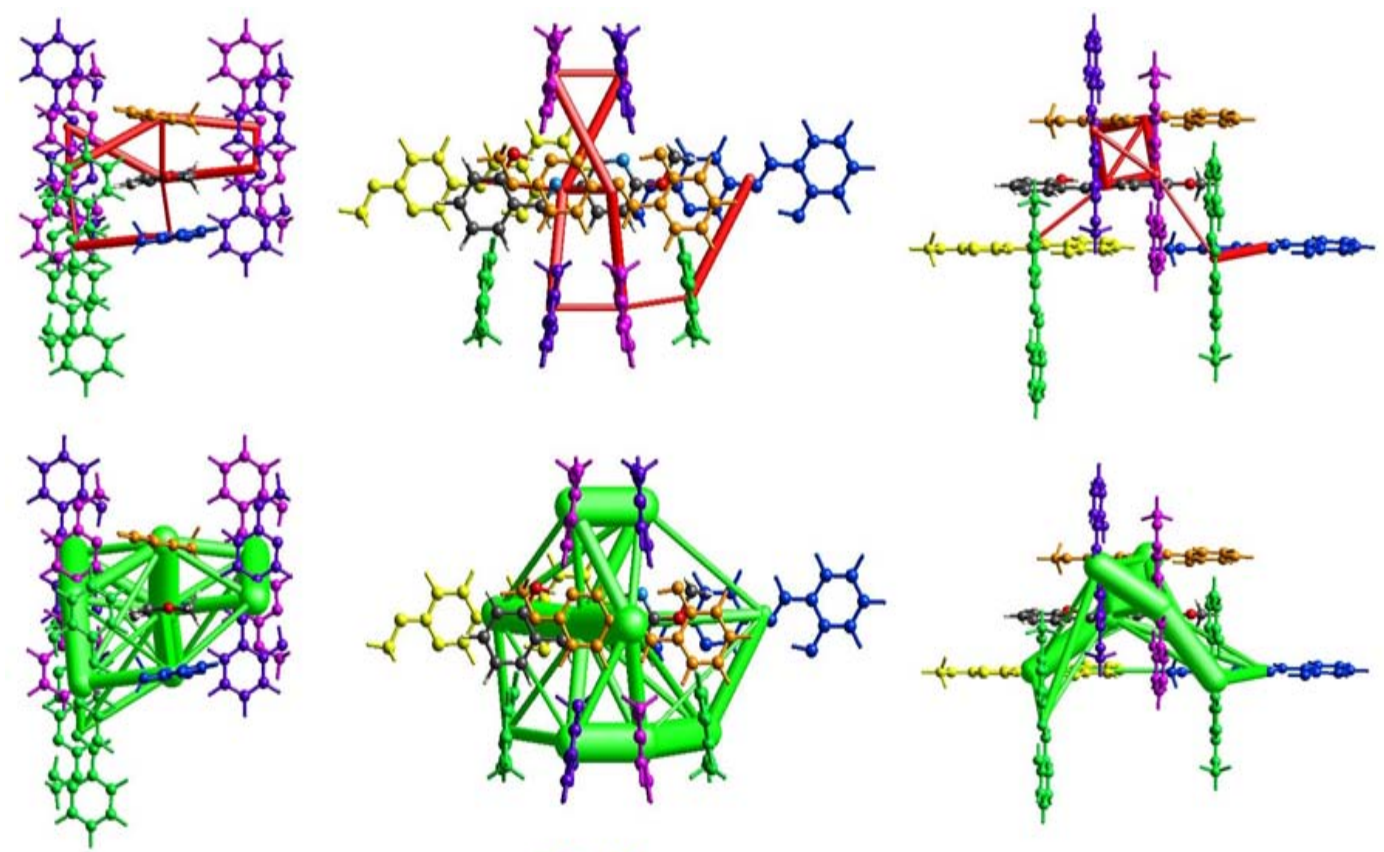

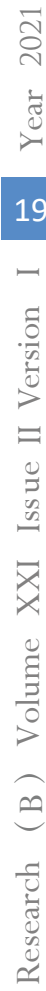

Fig. 9: The graphical representation of electrostatic interactions viz. coulomb interaction energy (red), dispersion energy (green), total interaction energy (blue) of the compound along different axes
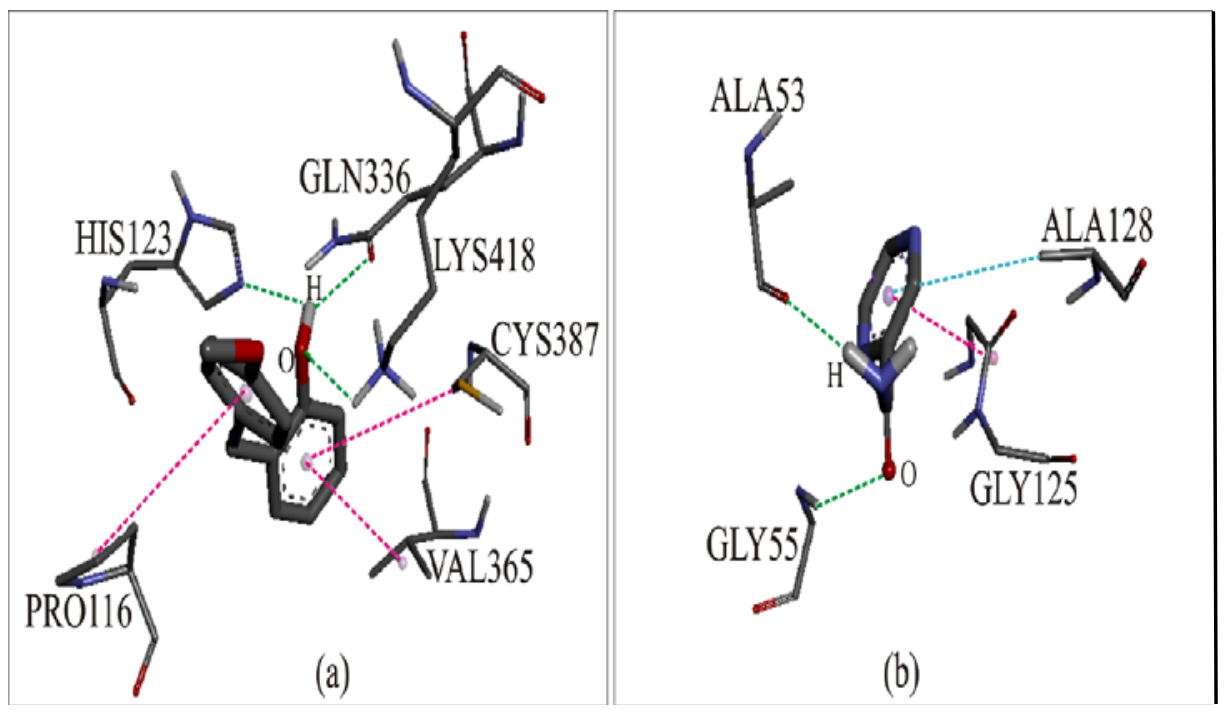

Fig. 10: Interaction of (a) MPIMP and (b) pyrazinamide to 4KW5 binding site 


\section{References Références Referencias}

1. A. Carreño, L. Rodríguez, D. Páez-Hernández, R. Martin-Trasanco, C. Zúñiga, D. P. Oyarzún, M. Gacitúa, E. Schott, R. Arratia-Pérez and J. A. Fuentes, Front. Chem. 6, 312 (2018).

2. A. E. Parlak, H. Cakmak, S. Sandal, B. Yılmaz, M. Sekerci, Z. KaragözGenc, M. Tuzcu and M. Karatepe, J. Biochem. Mol. Toxicol. 33 (2), e22247 (2019).

3. E. Yousif, A. Majeed, K. Al-Sammarrae, N. Salih, J. Salimon, and B. Abdullah, Arabian J. Chem. 10, S1639 (2017).

4. M. A. Malik, O. A. Dar, P. Gull, M. Y. Waniand and A. A. Hashmi, Med. Chem. Commun. 9 (3), 409 (2018).

5. A. B. Thomas, R. K. Nanda, L. P. Kothapalli, and S. C. Hamane, Arab. J. Chem. 9, S79 (2016).

6. M. B. Gawande, P. R. Nilkanth, S. Ghorai, K. Dhawale, S. Shelke and T. Ahamad, Chem. Biodivers. 17 (9), e2000342 (2020).

7. S. Murtaza, M. S. Akhtar, F. Kanwal, A. Abbas, S. Ashiq and S. Shamim, J. Saudi Chem. Soc. 21, S359 (2017).

8. D. Dewangan, K. T. Nakhate, V. S. Verma, K. Nagori, and D. K. Tripathi, J. Heterocycl. Chem. 54 (6), 3187 (2017).

9. Y. Y. Wang, F. Z. Xu, Y. Y. Zhu, B. Song, D. Luo, G. Yu, S. Chen, W. Xue and J. Wu, Bioorg. Med. Chem. Lett. 28 (17), 2979 (2018).

10. A. S. Hassan, H. M. Awad, A. A. Magd-El-Din and T. S. Hafez, Med. Chem. Res. 27 (3), 915 (2018).

11. D. A. Sabbah, F. Al-Tarawneh, W. H. Talib, K. Sweidan, S. K. Bardaweel, E. Al-Shalabi and M. S. Mubarak, Med Chem. 14 (7), 695 (2018).

12. A. A. Shanty, and P. V. Mohanan, Spectrochim. Acta A, 192, 181 (2018).

13. K. Karrouchi, L. Chemlal, J. Taoufik, Y. Cherrah, S. Radi, M. E. A. Faouzi, and M. Ansar, Ann. Pharm. Fr. 74 (6), 431 (2016).

14. M. S. More, P. G. Joshi, Y. K. Mishra and P. K. Khanna, Mater. Today Chem. 14, 100195 (2019).

15. A. M. Abu-Dief and I. M. Mohamed, Beni Suef Univ J Basic Appl Sci. 4 (2), 119 (2015).

16. M. J. Turner, J. J. Mckinnon, S. K. Wolff, D. J. Grimwood, P. R. Spackman, D. Jayatilaka, and M. A. Spackman, Crystal Explorer 17.5 (The University of Western Australia, 2017).

17. S. Bodige, P. Ravula, K. C. Gulipalli, S. Endoori, P. K. R. Cherukumalli, N. S. C. JN and N. Seelam, Synth. Commun. 49 (17), 2219 (2019).

18. J. Gawad and C. Bonde, Chem. Cent. J. 12, 138 (2018).

19. O. V. Dolomanov, L. J. Bourhis, R. J. Gildea, J. A. K. Howard, and H. Puschmann, J. Appl. Crystallogr. 42, 339 (2009).

20. G. M. Sheldrick, Acta Cryst. A71, 3 (2015).

21. G. M. Sheldrick, Acta Cryst. C71, 3 (2015).
22. L. Spek, Acta Crystallogr. D65, 148 (2009).

23. M. Nardelli, J. Appl. Crystallogr. 28, 659 (1995).

24. C. F. Macrae, I. J. Bruno, J. A. Chisholm, P. R. Edgington, P. McCabe, E. Pidcock, L. RodriguezMonge, R. Taylor, J. Van De Streek and P. A. Wood, J. Appl. Cryst. 41, 466 (2008).

25. G. M. Morris, R. Huey, W. Lindstrom, M. F. Sanner, R. K. Belew, D. S. Goodsell and A. J. Olson, J. Comput. Chem. (2009).

26. Discovery studio visualizer: http://accelrys.com/ products/collaborative-science/biovia-discoverystudio/visualization.html.

27. Z-L. Jing, R-N. Li, N and Yang, Acta Cryst. E63, o3001 (2007).

28. H. Unver, B. Boyacioglu, C. T. Zeyrek, D. Yolal, M. Yildiz, N. Yildinm, N. Demir, A. Kiraz and A. Elmali, J. Appl. Crystallogr. 48 (1), 32 (2018)

29. J. Bernstein, R. E. Davis, L. Shimoni and N. L. Chang, Angew. Chem. Int. Ed. Engl. 34, 1555 (1995).

30. M. A. Spackman and D. Jayatilaka, CrystEngComm. 11, 19 (2009).

31. J. J. McKinnon, D. Jayatilaka and M. A. Spackman, Chem. Commun. 3814 (2007).

32. M. J. Turner, S. Grabowsky, D. Jayatilaka and M. A. Spackman, J. Phys. Chem. Lett. 5 (24), 4249 (2014).

33. M. J. Turner, S. P. Thomas, M. W. Shi, D. Jayatilaka and M. A. Spackman, Chem. Commun. 51 (18), 3735 (2015).

34. A. J. Edwards, C. F. Mackenzie, P. R. Spackman, D. Jayatilaka and M. A. Spackman, Faraday Discuss. 203, 93 (2017). 